\title{
Islam y Mujer: a propósito de dos obras de Fátima Mernissi*
}

\author{
Carimo Mohomed**
}

\section{Introducción}

Uno de los tópicos que se suele asociar al Islam es el de la condición de la mujer, y, de acuerdo con él, la mujer en el Islam estaría en una situación de inferioridad y bajo las peores condiciones, siendo el velo, u otra prenda semejante, el símbolo mayor de esa condición, simbolizando todo un mundo de humillaciones y crueldad, y siempre que alguien pretende liberar a la mujer musulmana empieza por pedir que se quite el velo.

Sin embargo, estos y otros prejuicios son muy reductores y simplificadores, pues como dijo Zoreh Sefaty, una ayatolá iraní mujer, en una entrevista al periódico El País, el Occidente desconoce que el Islam no hace diferencias entre mujeres $y$ hombres. ${ }^{1}$ Por supuesto que hay que considerar esta declaración con alguna cautela, pero es un buen punto de partida para abordar el tema que tenemos ahora en manos, pues como ella también ha dicho, en Europa y en el mundo entero también las mujeres tienen problemas, porque una mujer es una mujer y un

* Resenha de MERNISSI, Fátima. Sueños en el umbral: memorias de una niña del harén. Barcelona, El Aleph, 2008, e El harén en Occidente. Madrid, EspasaCalpe, 2006. Recebida para publicação em fevereiro de 2011, aceita em março de 2011.

** Doutorando em Ciência Política na Faculdade de Ciências Sociais e Humanas da Universidade Nova de Lisboa (FCSH-UNL). Membro do NECI - Núcleo de Estudos em Contextos Islâmicos, do Centro em Rede de Investigação em Antropologia, e investigador do Instituto de História Contemporânea, na mesma faculdade. mohomed.carimo@gmail.com

1 Entrevista disponible en http://www.elpais.com/articulo/internacional/islam/ hace/diferencias/mujeres/hombres/elpepuint/20060612elpepuint_1/Tes 
Islam y Mujer

hombre es un hombre o como ha dicho John Lennon en una de sus canciones, 'la mujer es el negro del mundo'. Como ejemplo refiramos las noticias que casi diariamente salen a la luz y que hablan de la violencia de género, sea en España, en la India o en otras partes del mundo.

Según datos disponibles, entre el 40 y el 50\% de las mujeres de los países de la Unión Europea experimentan insinuaciones sexuales, contactos físicos no deseados u otras formas de acoso sexual en el lugar de trabajo. De acuerdo con las estadísticas, entre el 12 y el $15 \%$ de las mujeres en Europa sufren violencia doméstica $y$ algunas de ellas mueren en manos de sus compañeros, o ex compañeros afectivos. ${ }^{2}$ La egipcia Leila Ahmed ${ }^{3}$ ha denunciado la práctica del Occidente de utilizar la imagen de opresión de la mujer en el Islam para justificar sus objetivos políticos: como el Islam oprime a la mujer, y esto no va a cambiar, el abandono del Islam es el único camino para lograr la liberación de la mujer musulmana.

Lo que el feminismo islámico defiende es la posibilidad de que las mujeres musulmanas logren la plenitud de sus derechos en el marco del Islam, oponiéndose tanto al Islam patriarcal como al feminismo laicista que es contra el hecho religioso. Como ejemplo de esta última tendencia, tenemos otra egipcia, Nawal El Saadawi ${ }^{4}$ que califica de oprimidas a las mujeres musulmanas que se ponen ellas mismas el velo. Además, esta posición feminista de inspiración occidental, en lugar de ayudar a las mujeres

\footnotetext{
2 Más informaciones en http://www.saynotoviolence.org/es/el-tema/datos-y-cifras

3 De entre las obras de esta profesora de Estudios de Mujer en Religión, en la Harvard Divinity School, destacamos su Women and Gender in Islam: The Historical Roots of a Modern Debate (1992).

4 Para más informaciones sobre esta feminista egipcia nacida en 1931 - además de escritora, también es psiquiatra y ha sido activista política a lo largo de los últimos 60 años - véase su página web http://www.nawalsaadawi.net/.
} 
musulmanas, les complica la vida, como ha referido Asifa Quraishi hace algunos años en un encuentro en EE.UU. ${ }^{5}$

Curiosamente en el mundo llamado occidental hay ahora un debate sobre qué es el feminismo y qué es ser feminista. Si las primeras sufragistas lucharon para que la mujer saliera de su rol tradicional y que entrara en el mundo del trabajo, hoy en día una nueva escuela de pensamiento insiste que abrazar el papel de ser una madre que se queda en casa también es feminismo, siempre que eso sea lo que escoja.

El mundo al que se suele llamar de islámico es una entidad con una extensión geográfica planetaria, con sociedades tan diversas y dispares a nivel cultural, étnico, histórico, de tradiciones y costumbres etc. Así, hablar de mujer en el Islam es una abstracción que no explica nada: ¿de qué mujer(es) hablamos? ¿De qué Islam? ¿Dónde? ¿Cuándo? ¿Por qué? Por otro lado, muchos son aquellos y muchas son aquellas que consideran al Islam como base para la liberación de la mujer y que utilizan al Corán como instrumento a favor de esa liberación.

Ya en el siglo XIX dos hombres, Sayyid Mumtaz Ali (1860$1935)^{6}$ en la India y Qasim Amin (1865-1908) ${ }^{7}$ en Egipto, defendían en sus corrientes reformistas islámicas el elevar la condición de la mujer, denunciando el monopolio tradicional de los hombres, en particular de los ulemas, respecto a la lectura e interpretación

5 Más informaciones en http://www.stanforddaily.com/2006/05/26/ feminismcant-solve-all-muslim-speaker-advises/

6 Después de la Rebelión de 1857-58, que puso fin al poder político del Islam en la India e introdujo el gobierno británico directo, muchos fueron los musulmanes que intentaron reformar al Islam en la India como un todo. Las propuestas fueron variadas y una de ellas fue la de Sayyid Mumtaz Ali que se interesó por los derechos de las mujeres y que en su obra Huquq un-Niswan [Derechos de las Mujeres] (1898) abogaba por una mejora de sus condiciones.

7 Jurista, uno de los fundadores de la Universidad del Cairo y activista político en el movimiento nacional egipcio, Qasim Amin dedicó gran parte de su labor a la defensa de las mujeres, abogando por sus derechos, sobre todo con las obras Tahrir al mara'a [La liberación de las mujeres] y Al-Mara'a al-Jadida [La Nueva Mujer], publicadas en 1899 y 1900 respectivamente. 
Islam y Mujer

patriarcal y machista del Corán. Esas corrientes se han desarrollado en los últimos años y defienden el derecho de las mujeres a acceder directamente a los textos y a interpretarlos desde una perspectiva de género.

En estas dos obras de Fátima Mernissi que ahora analizamos, Sueños en el umbral: memorias de una niña del harén (2008) y El harén en Occidente (2006), se aborda la problemática del Islam y del feminismo. Fátima Mernissi, socióloga de renombre, investigadora de la Universidad Mohammed $\mathrm{V}$, en Rabat (Marruecos), y una de las voces más fuertes del feminismo en el mundo musulmán, nos habla de sus recuerdos a través de los sueños y de las fantasías de las mujeres que con ella compartieron su infancia, y de la perplejidad que fue la constatación, mientras viajaba por Europa y EE.UU. para promover su libro Sueños en el umbral, de que para la mayoría de los hombres occidentales la simple mención de la palabra 'harén' provocaba las más voluptuosas fantasías sexuales en las cuales el hombre conseguía dominar mujeres vulnerables cuyo único objetivo era satisfacer sus deseos.

\section{Soñando}

En Sueños en el umbral, Fátima Mernissi habla de su infancia en la casa de Fez, donde vivían su abuelo paterno, las esposas de éste, tíos, primos y otros familiares además de su padre y madre, y en la granja de su abuelo materno, donde vivían su abuela materna Yasmina además de otras co-esposas.

Además, habla de cómo su madre la educó e influyó para que no fuese una mujer sumisa. Al revés, la incitaba a que fuera fuerte. Como inspiración había los personajes de las Mil y una Noches como Scheherazade, que con su inteligencia y dominio de la palabra supo dominar al rey, su marido y hombre, o la princesa Budur que, disfrazándose inteligentemente de hombre, pudo sobrevivir y afirmarse delante los demás. Hace también referencia a la situación histórica que Marruecos vivía en esa época, con la 
presencia de españoles y franceses y la división del país, así como la situación histórica de la Segunda Gran Guerra.

Las hudud, o fronteras, eran muy importantes pues para ser feliz había que respetarlas. Podían ser las fronteras físicas que empezaban en la puerta de casa o podían ser las sociales que ponían los hombres en un sitio y las mujeres en otro. Sin embargo, desde joven Fátima Mernissi tenía anhelo en romper con las fronteras, ciertamente inspirada por su madre, su tía Habiba y por la abuela Yasmina, que hacía referencia al Profeta Mahoma y al hecho de que él nunca había hecho diferenciación entre hombres y mujeres o entre ricos y pobres.

Por otro lado, la autora se refiere a la ilusión que había en los años 40 y 50, del siglo XX, sobre el movimiento nacionalista marroquí que defendía una nueva época con nuevas leyes en las que las mujeres serían iguales a los hombres ante la ley, similar a lo que había ocurrido en Egipto y Turquía, y donde la modernidad, simbolizada, por ejemplo, por el idioma francés, podría coexistir con la tradición, simbolizada por todo lo que era árabe. Pero, casi cincuenta años después, la situación seguía igual, o incluso peor, en lo que a la poligamia y divorcio se refería.

Respecto al harén, que etimológicamente deriva del árabe haram, o sea, prohibido, sagrado o tabú, la autora describe las distintas situaciones: la vida en la ciudad era diferente de la del campo, pues aquí, donde vivía Yasmina y otras co-esposas como Tamu y Yaya, había mayor libertad y mayor contacto con la naturaleza, además de no haber todas las reglas que había en la casa y el harén de Fez.

Por otro lado, las mujeres tenían opiniones diferentes y opuestas en lo que se refería a la separación de hombres y mujeres y al papel del harén: había las que los defendían y había las que estaban en contra, como la madre de Fátima, que intentaba crear un futuro diferente del suyo para sus hijas a través, por ejemplo, de la prohibición de usar el pañuelo, o velo, y fomentando la utilización de prendas occidentales, consideradas como signo de modernidad. 
Islam y Mujer

Esta división entre las mujeres era motivo para que se hablase de la solidaridad femenina, asunto sensible para algunas que consideraban que la falta de tal vínculo hacía con que las mujeres estuviesen en la situación en que estaban y, por lo tanto, las mujeres eran las peores enemigas de ellas mismas.

Yasmina, que consideraba que las mujeres eran blanco de leyes crueles porque éstas eran hechas por los hombres y que solo cambiarían cuando ellas las hicieran, también tenía una opinión negativa sobre la forma como las mujeres eran tratadas pero creía en un futuro mejor para sus nietas. También tenemos una descripción de cómo las mujeres, sea en la ciudad sea en el campo, ocupaban su tiempo: en la ciudad trabajaban en el hogar $e$ intentaban divertirse con historias, idas al cine, que no solían ser muchas y que cuando ocurrían eran motivo para que las mujeres se arreglasen de la mejor manera posible; escuchaban la radio. Sobresalía la cantante libanesa Asmahan, que era motivo para que se hiciesen representaciones teatrales de su vida, considerada como modelo de lo que debería ser la moderna mujer árabe; además, hacían representaciones de la vida de mujeres famosas, particularmente las pioneras del feminismo árabe, como Aisha Taymur y Huda Sha'raui, egipcias, o Zaynab Fawwaz, libanesa, que defendían que la liberación de la mujer conduciría a la revitalización del Islam; en el campo había un gran contacto con la naturaleza.

Sin embargo, el harén no es el único asunto en el libro pues Mernissi igualmente aborda otros temas como las relaciones entre los diferentes 'cristianos', la guerra entre los alemanes y los franceses, la separación racial entre blancos y negros americanos o la felicidad que fue cambiar de una escuela coránica para una moderna al estilo francés. Pero el tema central es el ansia de libertad, simbolizada por las alas y por el vuelo. 
Carimo Mohomed

\section{El otro mira a la otra}

En El harén en Occidente, Fátima Mernissi habla de la sorpresa que fue para ella la constatación, mientras viajaba por Europa y EE.UU. para promover su libro anterior, de que para la mayoría de los hombres occidentales la simple mención de la palabra 'harén' provocaba las más voluptuosas fantasías sexuales, en las cuales el hombre conseguía dominar mujeres vulnerables cuyo único objetivo era satisfacerle sus deseos.

Este tópico ya había sido tratado, por lo menos, desde el siglo XVIII, cuando algunos ilustrados tenían semejante actitud para con el Islam. Como ejemplo hagamos referencia a Montesquieu que, a pesar de nunca haber estado en Persia/Irán, hizo en sus Cartas Persas referencias al harén, a la poligamia, al erotismo, a la promiscuidad sexual, o sea, aspectos que tanto deleite causaron y siguen causando en la imaginación europea y occidental, como Fátima Mernissi pudo constatar.

Por otro lado, en esas mismas Cartas Persas, las mujeres son retratadas como frívolas, tienen que obedecer al marido, su jefe y amo, y llevan una vida enclaustrada, prisionera, infeliz, son brutalizadas, vistas como objeto, permanentemente vigiladas por los eunucos pues se considera que ellas solo piensan en buscar el placer sexual y que son perversas, con pensamientos sucios. $\mathrm{O}$ sea, todo lo contrario de la actitud que Fátima Mernissi creía, y sigue creyendo, que los hombres musulmanes tienen a respecto de las mujeres: estas son inteligentes y, por lo tanto, peligrosas.

Por supuesto que las referencias al velo también existen en las Cartas Persas, lo que hacía que ningún hombre pudiera colocar la mirada en ellas, pues quien lo hiciese se arriesgaba a perder la vida. Para finalizar, las mujeres, de acuerdo a la óptica de Montesquieu, para los musulmanes, eran inferiores y no tenían lugar en el Paraíso. Sin embargo, Fátima Mernissi en El harén en Occidente dirige su mirada y atención hacia la cultura femenina del Occidente, en un reto al tópico de que las mujeres aquí tienen 
Islam y Mujer

sus derechos más asegurados que en cualquier otra parte del mundo.

\section{Conclusión}

La condición de la mujer en el Islam no es simple ni se puede reducir a unas pocas palabras, pues es una problemática muy rica y multifacética. Si es verdad que en algunas situaciones geográficas y culturales la mujer está en una situación de inferioridad y bajo las peores condiciones, la verdad es que muchas son aquellas y muchos son aquellos que intentan elevar su condición, respectando sus tradiciones, cultura y religión, o sea, aquello a que se suele llamar feminismo islámico, que defiende la posibilidad de que las mujeres musulmanas logren la plenitud de sus derechos en el marco del Islam, oponiéndose tanto al Islam patriarcal como al feminismo laicista.

La verdad es que hay muchas formas de ser feminista, de defender la elevación de la condición de la mujer, sea en Occidente, en Oriente, en el Norte o en el Sur, pero ¿cuál es la mejor forma o la verdadera? Para muchas, usar el velo u otra prenda semejante, no es símbolo de inferioridad, al contrario,, es una forma de afirmar sus creencias, cultura e identidad, al mismo tiempo que defienden la liberación de la mujer de las prácticas machistas.

Curiosamente, en los últimos tiempos, la industria de la moda respecto al hiyab está creciendo además que el velo no tiene porque significar opresión. Por otro lado, se puede constatar que el tópico de que el harén es un almacén de mujeres para que los hombres se satisfagan sigue en vigencia en Occidente, cuando en la realidad el harén es el lugar dónde están las mujeres de una casa, siendo esta como las antiguas oikos griegas o domus romanas. También hemos podido ver que muchas son las mujeres que defienden el status quo, no porque tienen recelo de los hombres sino porque así han sido educadas, provocando conflictos con las mujeres que piensan de otra manera. 
Para finalizar hay que subrayar que Fátima Mernissi se deparó en Occidente con actitudes y prácticas que, si en la forma son diferentes, en la esencia son iguales a lo que muchos acusan al Islam: la dominación de las mujeres por los hombres. La realidad de las culturas islámicas es diametralmente opuesta y la investigación de Mernissi denuncia una sucesión de equívocos y malentendidos. La misoginia, sea occidental sea oriental, limita y dificulta la comunicación entre culturas.

\section{Referências bibliográficas}

AHMED, Leila. Women and Gender in Islam: The Historical Roots of a Modern Debate. New Haven, Yale University Press, 1992.

MumTaz Ali, Sayyid. Huquq un-Niswan. Lahore, Dar ul-Isha'iat-ePunjab, 1898. 